\title{
Effects of low intensity UHF radio fields as a function of frequency'
}

\author{
SUSAN F. KORBEL AND HERBERT L. FINE
} UNIVERSITY OF ARKANSAS

Thirty six naive male rats were used as Ss in two experiments to deiermine a possible relationship between frequency of low intensity ultra-high-frequency radio ficlds and activity level. In Experiment 1, a low frequency range $1320 \mathrm{MHz}$ $450 \mathrm{MHz})$ was used, while a higher frequency range $(770$ $\mathrm{MHz}-900 \mathrm{MHz}$ ) was used in Experiment 2. Identical low power levels were maintained for both experinents $(.43 \mathrm{~mW}$ $.15 \mathrm{~mW}$ ). Although the application of both high and low frequency ranges resulted in decrissed activity, the lower frequencies were more cffective in producing the activity. change.

The ultra-high-frequency (UHF) region of the electromagnetic spectrum is defined as that frequency range extending from 300 megaHertz ( $\mathrm{MHz}$ ) to 3000 $M H z$. It is evident that the use of UHF radio waves for communication purposes is continuously increasing.

Investigations dealing with the effects of $\mathrm{UHF}$ radio waves have focused on the physiological effects as a result of exposure to UHF fields of relatively high intensity and high frequencies (Kholodov, 1967; Peyton, 1960). Behavioral studies have been neglected, particularly those involving the use of low intensity and low frequencies.

Experiments by Korbel (1966) and Korbel \& Thompson $(1962,1965)$ have demonstrated that relatively long-term exposure to low intensity, low frequency UHF fields results in behavioral changes in rats. Rats exposed to continuous ascending and descending sweeps of frequencies from 300 to $920 \mathrm{MHz}$ showed the following behavior 1 changes as compared to control Ss: (a) consistent, long term hypoactivity which may be preceded by a shist-term period of hyperactivity; (b) greater emotionality; and (c) longer latency of recovery from electroconvulsive shock. Since the frequency range of these behavioral studies was relatively broad, the present experiment was designed to investigate frequency parameters within this broad frequency range. Specifically, the task of this research was to determine the relationship, if any, between frequency of low intensity UHF radio fields and activity level.

\section{Subjects}

Thirty-six 28-day-old naive male Wistar rats were used as Ss in two experiments. Ss were randomly assigned to the two treatment groups within each experiment by the use of a table of random numbers. Apparatus

UHF fields were produced by a General Radio power supply (Type 1269-A) and a General Radio oscillator (Type 1209-B-250 to $920 \mathrm{MHz}$ frequency range). A circular discone antenna direrted the radio waves to the experimental Ss in their plastic living cages, these cages being arranged in a circle around the antenna. At all exposure times Ss were not more than $25-1 / 2$ in. nor less than $15-1 / 2$ in. from the antenna.

Within one large room, experimental and control groups lived in separate, identical comparturunts $(7 \mathrm{ft}$ 9 in. $x 5$ ft 9 in.), each compartment being completely lined with bronze screening. In addition, the living cages of each group were enclosed in a small bronze cage ( $5 \mathrm{ft} \times 5 \mathrm{ft}$ ). In the experimental group compartment all bronze shielding was grounded through $6 \mathrm{ft}$ rods driven into earth ground. The purpose of the shielding in the experimental compartment was to contain the RF energy within the experimental compartment, while the shielding in the control group compartment served chiefly as a control, i.e., to maintain identical environmental conditions in experimental and control compartments. In order to insure that the power level was held constant, daily power level measurements were made with an RF power meter (Hewett-Packard Model 431-A).

Activity was measured by using five activity boxes (18 in. $x$ 9-1/2 in.), each box being equipped with a Knight photocell relay, light source, infrared filter, and counter.

\section{Procedure}

In Experiment 1, nine experimental Ss were exposed to low intensity UHF field $(.43 \mathrm{~mW}$ to $.15 \mathrm{~mW}$ as measured at the front and back of the living cages, respectively) for 21 consecutive days. Since the experimental Ss were radiated at all times other than the times when activity measures were made, daily radiation exposure was of 22-1/2 h duration. A low frequency range was presented in continuous ascending and descending sweeps of $320 \mathrm{MHz}$ to $450 \mathrm{MHz}$.

Daily 15 min activity measures were made for each $\mathrm{S}$, By means of a table of random numbers, Ss were randomly assigned as to the order of measurement and as to placement in activity boxes. Activity of the nine experimental Ss was compared to the activity of the nine control Ss who were not exposed to the UHF field.

Procedures for Experiment 2 were identical to those for Experiment 1, with the exception of frequency level. In Experiment 2, experimental Ss were exposed to continuous ascending and descending frequency sweeps of $770 \mathrm{MHz}$ to $900 \mathrm{MHz}$.

\section{Results}

The data from both experiments were analyzed by a Type I mixed analysis of variance design (Lindquist, 
1956). Analyses revealed that the UHF-treated Ss were significantly less active than control $\mathrm{Ss}$ in both Experiment $1(\mathrm{~F}=7.56, \mathrm{df}=1 / 16, \mathrm{p}<.05$; difference between means $=19.5$ ) and Experiment $2(F=4.85$, df $=1 / 16, p<.05$; difference between means $=12.2)$. The treatment variance components for each experiment indicate that the variance due to UHF treatments is approximately 2.5 times greater in Experiment 1 (164.86) than in Experiment 2 (59.39).

Significant differences in activity through the 21 days were obtained in both experiments (Experiment 1: $F=5.47, \mathrm{df}=20 / 320, \mathrm{p}<.05 ;$ Experiment $2: \mathrm{F}=1.88$, $\mathrm{df}=20 / 320, \mathrm{p}<.05)$. The increase in activity through days would be expected since both experiments used young, rapidly growing rats. The interaction between UHF and days was nonsignificant in both experiments (Experiment 1: $F=1.22$, $d f=20 / 320, p>.05$; Experiment 2: $F=1.28, d f=20 / 320, p>.05)$.

\section{Discussion}

Not only do the results of this investigation substantiate the relationship between low intensity, low frequency UHF and behavioral changes in the form of decreased activity, but they also point to the importance of the frequency parameter. Although both high and low frequency ranges produce a decrease in activity, a greater contribution of the UHF effects on activity is made by the lower range of frequencies than by the higher range of frequencies. It may be concluded, therefore, that lower frequencies at a given power level are more effective in producing activity changes.

These data confirm previous findings made by the author in that the major effect of low levels of UHF radiation on activity is one of hypoactivity. However, these data do not show an early short-term period of hyperactivity as was previously found. This discrepancy is probably due to a slight increase in power levels in the present investigation relative to the previous experiments. The initial, more subtle short-term effect of hyperactivity may have been obscured by the increase in power level resulting in an early, consistent hypoactivity.

In summary, this research demonstrates that lower UHF frequencies are more effective in producing activity changes than are higher UHF frequencies. It may be concluded that frequency is a parameter which must be considered in experiments dealing with UHF effects.

\section{References}

KHOLODOV, Y. A. The effect of electromagnetic and magnetic fields on the central nervous system. Washington, D. C.: NASA Technical Translation, TTF-465, 1967.

KORBEL, S. Behavioral effects of electromagnetic radiation. Paper presented at the meeting of the Council for the Advancement of Science Writing, Oak Ridge Associated Universities, Nov. 1966.

KORBEL (EAKIN), S., \& THOMPSON, W. D. Effects of microwave radiation on activity level of rats. Psychol. Rep., 1962, 11, 192.

KORBEL (EAKIN), S., \& THOMPSON, W. D. Behavioral effects of stimulation by UHF radio fields. Psychol. Rep., 1965, 17, 595-602.

LINDQUIST, E. F. Design and analysis of experiments in psychology and education. Boston: Houghton-Mifflin, 1956.

PEYTON, M. F. (Ed.) Biological effects of microwave radiation. New York: Plenum Press, 1960.

Note

1. This research was supported in part by a National Science Foundation Grant, No. 12-5202, University of Arkansas. 